\section{HANKS, BOB}

the March 1956 issue of the Blue a special section of "Museum es" was inaugurated, and the e of Dr. R. W. Nero, the new tant director of the Saskatchewan seum of Natural History, first came the attention of the journal's lers. That date marked the beginof 21 years of continuous service he Blue Jay, a connection formally inated last fall when Bob resignrom the editorial staff. No one has a longer association with the Blue n an editorial capacity, and it will xtremely difficult to replace him. ough Bob will no longer be listed in assistant editor, the Blue Jay umes to hope that from his itoba base he will continue to enrage the reporting of natural ry observations by many kinds of ple, professional and amateur. le we look forward to further ributions from Bob, this seems an opriate time to say a special nk you" to him for his long and I service in the past.

reader in a reminiscent mood has just reminded us of all the articles on birds and mammals that Bob himself has contributed to the Blue Jay. When he worked at the Museum in Regina or Winnipeg he saw it as part of his professional responsibility to publicize what was being learned about the local fauna. Articles on the distribution in Saskatchewan of species like the Kangaroo Rat, Shorttailed Shrew, Pocket Mouse and Silver-haired and Hoary bats, alternated with others reporting the rare occurrence in the province of birds like the Arctic Tern, Williamson's Sapsucker, Red-bellied Woodpecker and Golden-crowned Sparrow. More than two columns in the Blue Jay indexes are devoted to the titles of notes and articles by R. W. Nero. But even more important, he instilled in others a sense of the importance of recording observations and of reporting them. From the first, Bob was an ardent fan of the Blue Jay's founding editor, Isabel Priestly, a scientist with the same rare capacity of sharing her informed awareness with others.

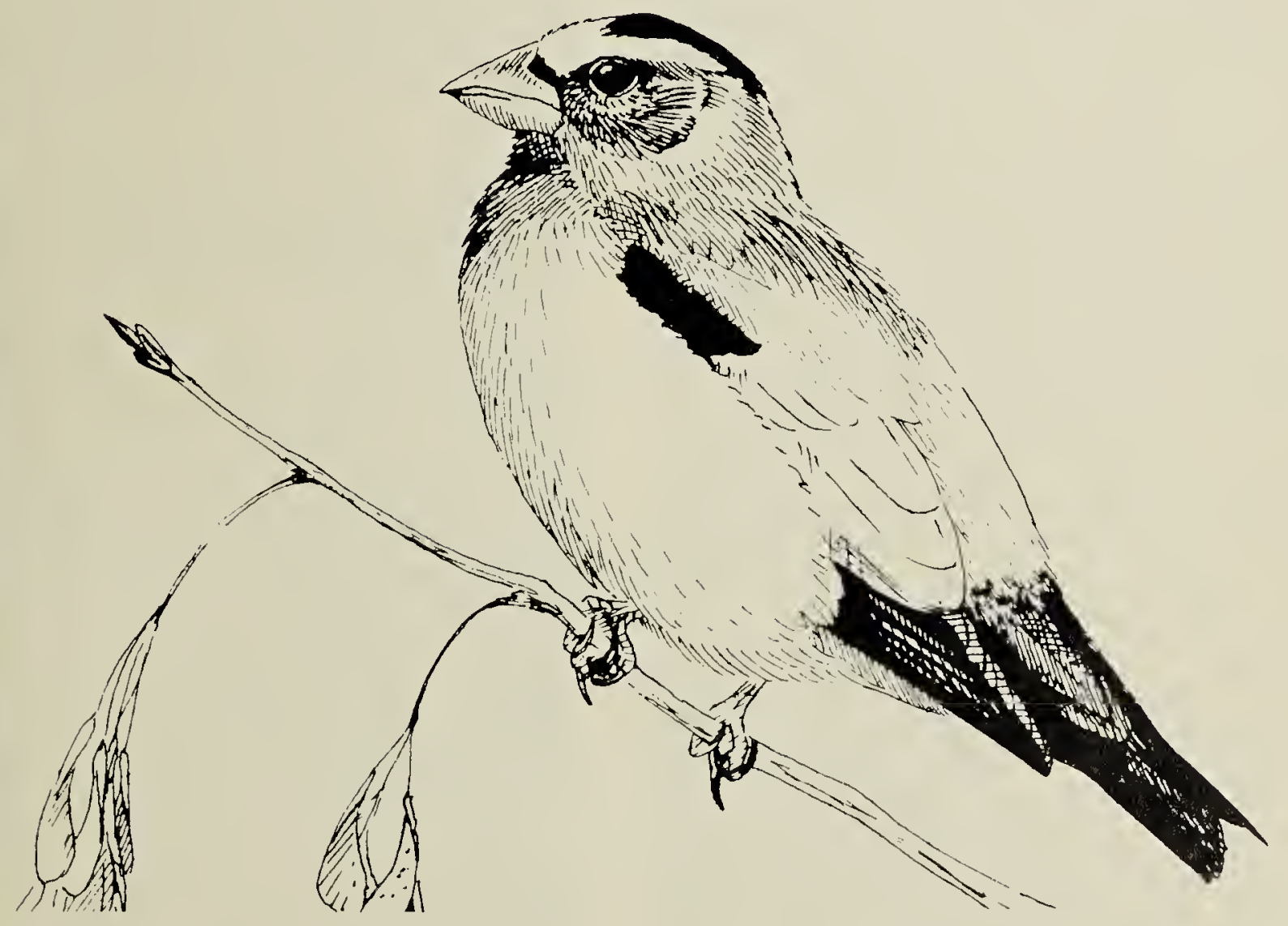

ing Grosbeak

Dwayne Harty 